\title{
Impartiality and accuracy as a case in point while interpreting in a refugee context
}

\author{
Amparo Jiménez Ivars \\ Universitat Jaume I
}

\begin{abstract}
This paper examines the fundamentals of professionalism focusing on the code of ethics as a pivotal parameter. Attention is paid to the difficulties of implementing two of the core principles of codes of ethics for interpreting in a refugee context: impartiality and accuracy. The aim of this article is to explore interpreters' appreciation of these principles and self-identification with them versus actual observance in refugee settings. Ninety-six US-based interpreters completed a survey on self-perceptions regarding adherence to the principles and real actions performed. Findings show that a high number of interpreters do not comply with the principles despite having previously declared their full endorsement and self-identification with them. Impartiality presented more deviations than accuracy. Internal and external demands have proven to be stronger than adherence to the code. Calls to rethink and refine codes of ethics for interpreting in a refugee context are also presented.
\end{abstract}

Keywords: interpreting, refugees, code of ethics, impartiality, accuracy

\section{Introduction}

The right to an interpreter for asylum seekers was implicitly set in the 1951 Refugee Convention signed by almost 150 countries. The convention enshrines the right to asylum for any person who fears persecution for reasons of race, religion, nationality, social group or political opinion. When applicants do not speak the language of the country, states must comply with the responsibility of translating for asylum applicants implying therein the right to interpretation. In order to establish whether a claimant qualifies for asylum, they must usually undergo a screening interview. It is also the responsibility of the interviewer to listen carefully to the applicant's case, to ask questions and assess whether or not they meet the legal criteria to obtain refugee status eventually (UNHCR, 2009). Most asylum processes usually involve several interviews or hearings during which the 
claimant must defend their case in different institutional settings: immigration or police premises, detention centres, attorney offices, courts, etc. The success or failure of an application rests on the credibility of the oral account that supports the claim, which, often, requires the assistance of interpreters bound by rules of professional conduct.

This article aims at examining interpreting practices by trained professionals during the asylum process and their relation with two of the core principles of interpreting codes of ethics: impartiality and accuracy. The first part of the article briefly examines the fundamentals of professionalism focusing on the code of ethics as a pivotal parameter. Attention is paid to the difficulties of implementing two of the core principles of the codes in a refugee context: impartiality and accuracy. The second part presents the findings of a survey on interpreters' appreciation of these principles and their actual observance in these settings. The geographical scope of the study is the U.S.A.

\section{Fundamentals of professionalism}

Hebenstreit, Marics \& Hlavac (2017:74) describe professionalism as:

[...] the particular manner in which one carries out one's duties. Professionalism is shown when a person fulfils the requirements of their occupation and displays field-specific knowledge or capabilities. Further to this, professionalism is understood to be the ability to employ specialist problem-solving skills, to follow fieldspecific behavioural norms and to be able to perform things that cannot be expected of lay people.

Professionalism is attained during a more or less long process often full of struggles. This process is known as professionalization, which refers to the process either at an individual or collective level. At an individual level, in order to become professional, a period of tertiary education, vocational training, experience and/or licensure or registration is required (Evetts, 2013). Bossers et al. (1999) allude to a multifaceted construct made up of three different categories: professional parameters, professional behaviours and professional responsibilities. Parameters refer to the legal and ethical realm; behaviours include specialized knowledge, skills and attitudes and responsibilities include responsibility to the profession and to all the stakeholders including the community as a whole.

Boeri (2015:41) focuses on professionalism as a social parameter for interpreting practitioners. She identifies the following features as part and parcel of professionalism. A set of moral values and principles established in a code of ethics; standards practice; consensual definitions of role and function; a body 
of theoretical and practical knowledge that serves as basis for formal training programmes; a system of licensure, registration or accreditation; an interpreting industry regulated by relevant sector agencies; a professional body that is representative of practising interpreters and an established governmental and/or institutional interpreting policy. Yet, the explicit moral values, principles, role, function and industrial protocols do not always enjoy universal consensus. In this respect, Rudvin (2007) asserts that professionalism is a social practice bound by culture that is not necessarily shared across cultures.

Regardless of how professionals interpret their occupational ethics, attitudes, conduct and boundaries, being aware of them contributes to achieving good performance even on their first day at work. Professionals know they must follow specific consensual protocols. They also know the optimal level of professional competences required in each situation. They are aware of their own limits and prepared to keep learning so that standards of quality are ensured. Rudvin (2007:50) captures the purpose and essence of professionalism in this sentence: "Gaining and maintaining credibility as an occupational group towards the public and those served".

\section{Codes of ethics for interpreters}

According to Tseng (1992), codes of ethics embody professional struggles and represent an attempt to organise market disorder. They are developed by professional associations with the aim of serving as guidelines for professionalism reflecting a consensus of thought. Interpreters' codes are considered helpful and necessary for the process of professionalization (Roberts 1997; Valero-Garcés 2006). The most professionalised sectors of interpreting, conference and legal interpreting, were the first to create associations of practising professionals that drafted codes of ethics. In the case of conference interpreting, the first code dates back to 1957 (AIIC) and has since vastly influenced subsequent national and supranational codes that apply to different realms. Professional associations or official bodies developed over time codes for conference, legal, health or refugee interpreting. These associations sometimes also identify a number of personal traits or skills that make up professionalism in interpreting.

Public Service Interpreting (PSI), which encompasses language mediation in settings other than conferences or the judiciary, continues to be the least professionalized sector. Consequently, there are very few national or international associations and codes. Canada, Australia, the UK, and Scandinavian countries are some of the few countries that have developed codes of ethics for PSI in general. These countries as well as the US do have specific codes in place for med- 
ical interpreting. In the US, there is at least one code proposed for PSI developed by a private initiative (García-Beyaert, Bancroft, Allen, Carriero-Contreras, \& Socarrás-Estrada, 2009) hut to our knowledge, no association has adopted it yet. The less professionalised (2017:250) posits that "codes are indeed intended to transform the social context where the PSI profession exists and they do this by pointing out elements that earn the profession trust and legitimacy".

Despite enormous differences in communicative situations, modes of interpreting, power relations, remuneration and social recognition, codes of ethics for interpreters almost unanimously share the following three main tenets: confidentiality, accuracy and impartiality. These principles were established in the first AIIC code and subsequently introduced in every sector of interpreting regardless of users and situations. Confidentiality or secrecy, that is, not disclosing any information learned during the execution of professional duties, is a highly valued principle embedded in every code almost verbatim. Accuracy is understood as the rendering of the message without any alteration, addition or omission of content or intention. It also involves the use of the first person. In order to render the exact meaning, clarifying is considered part of accuracy. Impartiality refers to refraining from allowing personal beliefs or feelings to manifest during interviews. Counselling, advising or engaging in private conversation with the parties also goes against impartiality and implies exceeding role boundaries. Any conflict of interest is assumed to affect impartiality (Hale, 2007).

Drawing on an ethical perspective, Hebenstreit, Marics \& Hlavac (2017:73-76) define these principles in terms of virtues and moral values for interpreting in a refugee context: Confidentiality and impartiality embody virtues that promote personal values such as confidence, self-determination and equality. These authors add the value of fairness to impartiality, meaning that actions must not be deliberately biased. Accuracy constitutes a manifestation of the individual values of truth, clarity and understanding, all associated with justice and equality, honesty, determination and fairness (ibid 73). Baixauli (2017:261) posits an ethical and philosophical relationship that binds the two principles here discussed. Accuracy requires impartiality and impartiality is necessary to render accuracy. They are both built on the notion of faithfulness, a discursive concept described by Inguilleri (2010:153) as "independent of social or institutional practices, individuals or history".

Yet, also based on ethical grounds that extend beyond the user's agency, some healthcare interpreting codes defend a more flexible approach regarding the three core principles if the health of the patient or other people could be in danger (NCIHC, 2004) or if advocacy or intercultural mediation is indispensable (IMIA, 2006). At the other extreme, court interpreting contains the most restrictive codes 
in terms of interpreter agency as can be seen in the following code excerpts: "All hedges, false starts and repetitions should be conveyed" (NAAJIT, 2016:12). The EULITA (2013) and NAAJIT (2016) codes establish that "interpreters should not converse with parties, witnesses, jurors, attorneys, or with friends or relatives of any party" following a model code proposed by Hewit in 1995. Some standards are even enshrined in law like in the Pennsylvania Rules of Professional Conduct for Judiciary Interpreters (2006): "Every spoken statement, even if it appears unresponsive, obscene, rambling, or incoherent should be interpreted. This includes apparent misstatements". An approach that clearly favours literalness and interpreter invisibility.

NAAJIT's recommendation of professional judgment and common sense when applying the code (NAJIT, Professional Judgment Caveat) does not seem to offset the severity of the specific rules since it lacks specificity. The rest of principles contained in codes vary to a certain extent depending also, on whether they are codes of ethics (values and principles) or standards of practice (guidelines and prohibitions). In this sense, issues such as direct communication, transparency, role boundaries, cultural competence, intercultural communication, continuous education, professional conduct, respect, collegiality, impediments to compliance, etc. are sometimes included to differing degrees of specificity.

\subsection{Codes of Conduct for interpreting in a refugee context}

Canada, Australia, Belgium, Finland and the UK are some of the few countries that have a specific code in place. This paper is going to focus on the code developed by the United Nations High Commissioner for Refugees due to its supranational nature (Self-Study Module 3: Interpreting in a Refugee Context UNHCR, 2009). This code of conduct is meant to guide UNHCR interpreters in maintaining professional behaviour and in making ethical decisions. As any code of conduct, its scope is narrow and contains specific actions. It is mandatory and must be signed by all UNHCR interpreters with the specific understanding that any violation of the code may result in withdrawal from employment for the high commissioner.

The code enshrines compliance with the following conditions: Linguistic accuracy and neutrality refers to the obligation to interpret content without adding, omitting or altering anything. It also explicitly states that cultural beliefs or practices must be handled with care. These must only be clarified if both parties agree that they require double-checking. The interpreter will also refrain from adding sociological, anthropological or cultural information. The impartiality principle prohibits interpreters from: a display of judgment, speaking on behalf of any party, giving legal advice or trying to influence results. It also pro- 
hibits them from acting when they are involved with the assignment except in emergencies provided all parties agree. Confidentiality refers to the prohibition of disclosure of any information obtained in the course of work at UNHCR for any reason, unless required by law enforcement. Acceptance of assignment, meaning that the interpreter's level of linguistic competence, physical and mental aptitude, potential conflict of interest, and personal feelings must not represent an obstacle to professional behaviour. The rest of the principles allude to general professional behaviours such as punctuality, preparation, attire, respectfulness, refusing any additional compensation for services and not making use of their position to secure privileges. The code is applicable as far as all users of interpreting services -particularly the staff- are aware of it and have been trained to work with interpreters so that they know what to expect from them.

As is apparent from the precedent descriptions of principles, the consensus is that the interpreter's' role is confined to a vehicle to facilitate communication detached from specific circumstances. Any other roles like informer, fact gatherer, consultant and adviser, as well as assistant must be supressed. Hebenstreit, Marics \& Hlavac (2017:73-76) underscore that impartiality, accuracy plus integrity are of key importance when interpreting in asylum procedures. The first two tenets fit within the conduit role of passing messages back and forth. This role ultimately aims at achieving interpreter invisibility and trying to create the illusion of a dyadic communication encounter. As stated by conference interpreting standards "interpreters should make the audience forget they are hearing the speaker through the interpreter" (AIIC, 1990: sec. 3:3). Still, experience and research show that the role and boundaries of the interpreter is not so clear-cut and restricted since the position of the interpreters has been proven to change throughout the communicative event (Roy, 1999; Wadensjö, 2001; Angelelli, 2004; Angermeyer, 2015).

\section{Interpreting for refugees in practice}

The asylum process in most countries is supposed to be non-adversarial (Tipton \& Furmanek, 2016:83). Nevertheless, the recipient countries' assumption is that applicants do not qualify for refugee status until proven thus, claimants have to prove their case by retelling their often traumatic experiences. For some scholars like Bahadir (2010), the process is described as a series of frictional encounters that may pose ethical dilemmas for interpreters even in non-adversarial situations, sometimes described as dispassionate and disinterested (Lakoff, 1989 cited in Fenton, 2004). Todorova (2017) claims that interpreters are not outsiders to the conflict but positioned inside the conflict situation and hence, can be at least one 
of the parties to that conflict. Consequently, interpreters frequently face a challenging task in the midst of two conflicting goals. Handling emotions that may arise due to the traumatic events that must be recounted (Keselman, Cederborg, Lamb \& Dahlström, 2010) is an additional challenge. Barbarem-Call et al. (2012) refer to this kind of interpreting for survivors of torture, trauma and sexual violence as "extreme interpreting". These authors, along with other scholars (Splevins et al. 2010) highlight the intensity, complexity and potentially injurious consequences it can cause to interpreters to the extent that Bancrof (2017) has called for the implementation of trauma-informed interpreting care.

These features and circumstances have led a high number of scholars to openly criticise or even dismiss the notion of impartiality in this setting describing it as inapplicable (Davidson, 2000: 401; Patel, 2003; Tymoczko, 2003; Pöllabauer, 2004; Dragovin-Drouet, 2007; Baker, 2006). Todorova (2017:119) posits that neutrality is "not only impossible but its opposite may actually be more effective to conflict resolution" in agreement with Barsky (1996) who stated that impartiality while interpreting was undesirable in the asylum process. He pleaded for a legal extension of the role of the interpreter to become active intermediaries. Interpreters, on their part, have often indicated that for any successful encounter to take place, they are required to assume roles beyond that of a mere conduit of words (Metzger, 1999; Hatton \& Webb, 1993; Dysart-Gale, 2005); a fact that became apparent in the early empirical studies in public service interp的 $\mathrm{E} g$ (Roy, 1999; Wadensjö, 1992). Yet, which roles these represent is one the most argued topics in the scholarly debate (Kaczmarek, 2016:58). The 2007 Declaration of Granada adopted at the 1st International Forum on Translation/Interpreting and Social Activism confronted the long established professional principles, openly stating that "the work of translators and interpreters is not limited to acting solely as a neutral conveyor of ideas between cultures" (Granada Declaration in Boeri \& Maier, 2015).

Be that as may, it cannot be denied that the asylum process is one of the most difficult contexts in which to maintain the conduit role (Pollabauer, 2004). If trained professionals and scholars acknowledge the difficulties of remaining impartial, it is not surprising that untrained practitioners, unaware of any principles or guidelines may feel their mission is to help either party (Bancroft, Bendana, Bruggeman, \& Feuerle, 2013). These authors claim this is even truer when interpreters are, or were, themselves refugees. This sense of obligation to assist others in the same position is particularly keen when they believe that their own asylum cases were lost (or nearly lost) due to inaccurate interpreting. A feeling that can be compounded by the asylum-seekers high expectations of the role of the interpreter as their ally or counsellor (Tribe \& Morrissey, 2003; Fenton, 2004; Hsieh, 2008; Fatahi, Nordholm, Mattsson \& Hellström, 2010). Authorities, 
for their part, may also expect, or demand, that interpreters align with them especially, but not only, when they are staff members (Hwa-Froelich \& Westby, 2003) adopting the role of the provider's assistant (Granger \& Baker, 2002; Leanza, 2005; Merlini, 2009; Kaczmarek, 2016).

Engaging in culture mediation, conflict mediation (Greenhalgh, Robb \& Scambler, 2006) and advocacy is strictly prohibited for court interpreters but according to Bancroft et al. (2013) most PSI in the US, who have received little to no training at all, are expected to perform these roles as well as to make efforts to ensure successful communication. Oftentimes, even when they are not directly expected or instructed to engage in active roles, interviewers are lenient when interpreters overstep impartiality (Tipton \& Furnamek, 2016).

Professional codes of ethics, through appeals to linguistic accuracy and impartiality, attempt to offer safeguards from taking decisions that would lead to lost neutrality and assume positions of power and authority. However, the internal and external demands above described are hard to overcome, especially when decisions have to be made in split seconds. Awareness of the principles should nevertheless, lead interpreters to make the best decisions for both parties even if that means deviating from the codes when some principles conflict with each other or with one's personal ethics (Inghilleri, 2012).

\section{Method}

In order to explore the state of affairs regarding the level of professionalism and working conditions of interpreters involved in language support for asylum seekers in the US, a major research project was conducted. The project covered seven main areas. 1. Demographics and professional profile. 2. Adherence to professional principles and standards of practice. 3. Attitudes and actions performed while interpreting. 4. Working conditions and difficulties. 5. Job satisfaction. 6. Identification of weaknesses in the language support service and suggestions to improve them. 7. Service providers' satisfaction with the language support system. This paper will only focus on the first three areas. The main objective of the present study is to identify trends and gaps in the practice of interpreting regarding practitioners' appreciation of impartiality and accuracy and compare it with their actual observance through self-perceived attitudes and actions. For the purpose of this study, respecting role boundaries will be included within the impartiality principle since this tenet may be compromised when the interpreter's role goes beyond that of a conveyor of ideas between languages and cultures. Similarly, completeness of delivery will also be included in the concept of accuracy. 


\subsection{Research design and procedure}

An online questionnaire for interpreters in a refugee context based on LeonPinilla (2015) was designed and subsequently reviewed by two experts. Those items identified as ambiguous or redundant were reworded or deleted in an effort to reach an interjudge agreement. The final version deviated significantly from the original. It consisted of 27 multiple-choice questions (that included 6 open-ended logic questions $)^{1}$ and 8 open-ended questions covering the seven areas above mentioned. The estimated completion time was 20 minutes. The questionnaire was prepared using Qualtrics Research Suite, an online survey tool that allows researchers to build, distribute, and analyse online surveys in real time. The multiple-choice questions used a three-point scale recommended by the online platform for statistical utility. Respondents had to indicate whether they agreed, disagreed or remained neutral, whether the statement was important, unimportant or neutral or whether the action or condition was met always, sometimes or never. The neutral position is usually considered tantamount to undecided or uncertain, or it depends on referred to actions or conditions ("I do (verb) + object"). When asked about actual compliance with the code, questions were worded as actions related to their experience. Items within questions were randomized for each participant independently.

For this study, only the following sets of questions were analysed: sociological questions (Q. 1-21), questions referred to appreciation of the principles (Q22), and those referring to attitudes and actions (Q. 23), presented in Appendix 1. The questionnaire was completed using the same Qualtrics online platform. A link to the survey with a presentation note was directly emailed to some 800 US-based interpreters whose addresses were found in interpreting agencies' websites and in the ATA (American Translators Association) database. It was also sent to the Texas certified court interpreters' directory made up of 400 interpreters -an undetermined number of them must have received double postings. The link was also posted in US professional and social network sites for interpreters. After participants had given informed consent, they had to confirm whether they had interpreted for asylum seekers. Those who had were allowed to continue. Data were collected in March 2019.

\subsection{Participants}

Ninety-six respondents completed the survey. Almost 80 per cent (79.8) of them were over 40 years old, 16.8 percent and 3.4 percent were under 30 . The percent-

1. Clarifications that were to be answered by those participants who chose an extreme option. 
age of female interpreters outweighed the male, 76.4 vs. 23.6 percent. Spanish and English were the main mother tongues, making up 34.8 percent each. 61.8 percent had some kind of higher education (completed or uncompleted), 12.35 percent had a master's degree, and there was one doctoral degree. One percent only had high school education, 93.3 had had some kind of training in interpreting. Practitioners with non-European language combinations had mostly taken short courses. Almost 60 percent were in possession of an official certification. Fifty percent of the sample also had had specific training to work in immigration settings and more than half had remote interpreting experience. Almost 80 percent were freelance contractors, 12.3 percent were staff. About 50 percent worked in Texas and California, and English-Spanish was the main language combination accounting for 64 percent of the sample. The graphic shows a summary of sociological details. A full description of the professional profile can be found in Appendix 2.

Table 1. Summary of sociological profile of the sample

\begin{tabular}{lll}
\hline Age & $79.8 \%$ & $>40$ \\
$16.8 \%$ & $30-40$ \\
& $3.4 \%$ & $<30$ \\
\hline Gender & $76.4 \%$ & Female \\
\hline Mother tongue & $34.8 \%$ & English \\
& $34.8 \%$ & Spanish \\
\hline Working language & $30.4 \%$ & Other languages \\
combinations & $69 \%$ & English-Spanish \\
\hline Job status & $36 \%$ & Other language combinations \\
& $78.7 \%$ & Contract freelancers \\
& $9 \%$ & Volunteers within non-profit organizations. \\
& $6.7 \%$ & Agency's employees \\
& $3.4 \%$ & Non-profit organization's employees \\
& $2.2 \%$ & Government employees \\
\hline Higher education & $38.2 \%$ & Graduate degree in one of the following: Spanish, \\
& Translation and Interpreting, Business, Law, \\
& International Relations, Education, Applied \\
& Linguistics, Communication, History, \\
& Humanities, Music, Computing. \\
\hline &
\end{tabular}


Table 1. (continued)

\begin{tabular}{lll}
\hline $\begin{array}{l}\text { Translation and/or } \\
\text { Interpreting higher } \\
\text { education }\end{array}$ & $12.35 \%$ & B.A or M.A. in Translation and/or Interpreting \\
\hline $\begin{array}{l}\text { Unfinished higher } \\
\text { education or associate } \\
\text { degree }\end{array}$ & $61.8 \%$ & \\
\hline $\begin{array}{l}\text { Only high school } \\
\text { or less }\end{array}$ & $1 \%$ & \\
\hline $\begin{array}{l}\text { Some training } \\
\text { in Interpreting }\end{array}$ & $90.4 \%$ & $\begin{array}{l}\text { State-certified court interpreters, Federally- } \\
\text { certified court interpreters, Professionally- } \\
\text { qualified court interpreters, NAJIT diploma RID } \\
\text { diploma, Certified medical interpreters }\end{array}$ \\
$\begin{array}{l}\text { Official certificate } \\
\text { in interpreting }\end{array}$ & $59 \%$ & Yes \\
\hline $\begin{array}{l}\text { Training to work with } \\
\text { asylum seekers }\end{array}$ & $49.5 \%$ & $>20$ years \\
\hline $\begin{array}{l}\text { Experience with } \\
\text { asylum seekers }\end{array}$ & $36 \%$ & A 10 years \\
\hline Settings & $30 \%$ & interview, Detention centers, Medical care. \\
\hline
\end{tabular}

These data show that participants constituted a quite homogeneous sample. More than three quarters of the participants were women and the main language combination was English-Spanish. However, age became the most outstanding sociological feature: an overwhelming majority were over 40 whereas only three were under $30 .{ }^{2}$ Most were court interpreting certified and virtually all of them declared themselves to have had interpreting training. Hence, we can conclude that respondents, who also had a long professional record, were fully-fledged trained professionals, thereby bound to be familiar with the core principles of professional ethos and standards of practice.

2. It is worth commenting here that PSI is an aging profession due to a number of reasons, most notably to the "privatisation and outsourcing of public services that hinder professionalization and damage the public perception of the profession" (Gentile, 2017: 69). Other reasons are an increasingly less favourable attitude to immigration worldwide that has taken its toll with regard to institutional provision (or lack of) of language services. This fact has had a detrimental effect on wages resulting in younger generations' lack of interest in PSI. 


\subsection{Results}

\subsubsection{Appreciation of the selected principles of the Code of Ethics}

Impartiality, accuracy and completeness of delivery as part of accuracy were rated as relevant by more than 95 percent of the sample (Graph 1). Impartiality and completeness of delivery achieved the highest score, 97.8 percent. 2.2 percent rated both principles as irrelevant and none opted for the midpoint (either agree or disagree). Accuracy scored 95.7; 4.3 percent showed a neutral stand and none considered this principle irrelevant.

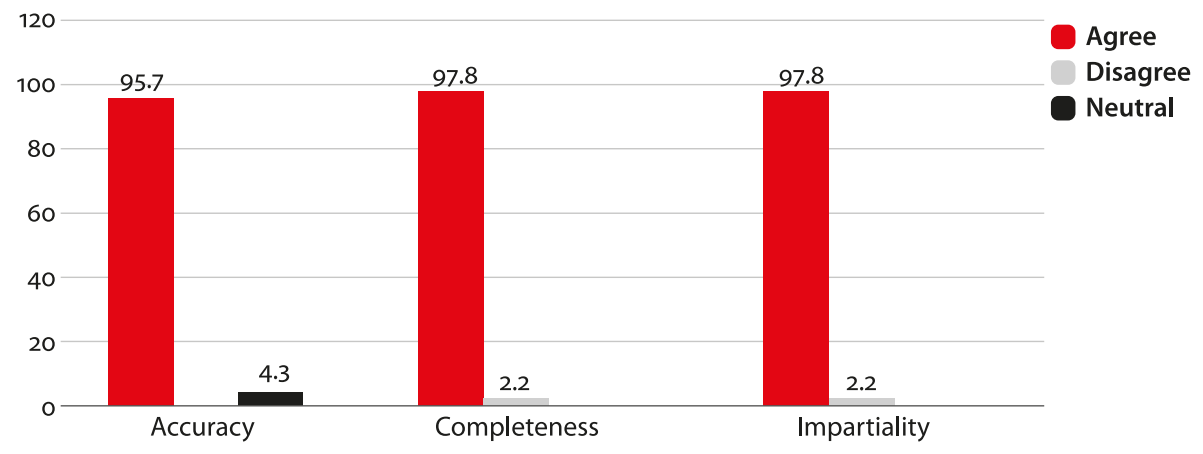

Graph 1. Appreciation of the main tenets of the Code of Ethics

\subsubsection{Attitudes and action related to the principles}

Impartiality. 88.6 percent of respondents identified themselves with the action I remain impartial while interpreting. This is A commitment level slightly lower than the previous almost unanimous rate of high esteem for the principle. When asked about specific actions, the majority, but not all, acknowledged that they behave accordingly. Only one impartial action was 100 percent explicitly endorsed, namely, no one directly admitted answering whether the claimant is trustworthy or not, although 12.5 percent opted for the neutral position. It must be pointed out that 10.4 percent recognised that staffers ask them if the applicant is telling the truth. Graph 2 shows all responses. Percentage figures can be seen in Appendix 3.

The rest of the items show breaches of the principle to a different degree as shown in Graph 3. The most outstanding non-compliance with the rules were the following: offering moral support, 45.5 percent; standing by the asylum seeker 27.3 percent; taking control of the situation $17 \%$ and calming the asylum-seeker down, 14.8. Participants admitted to engage in all remaining non-impartial actions, though to a much a lower extent. 


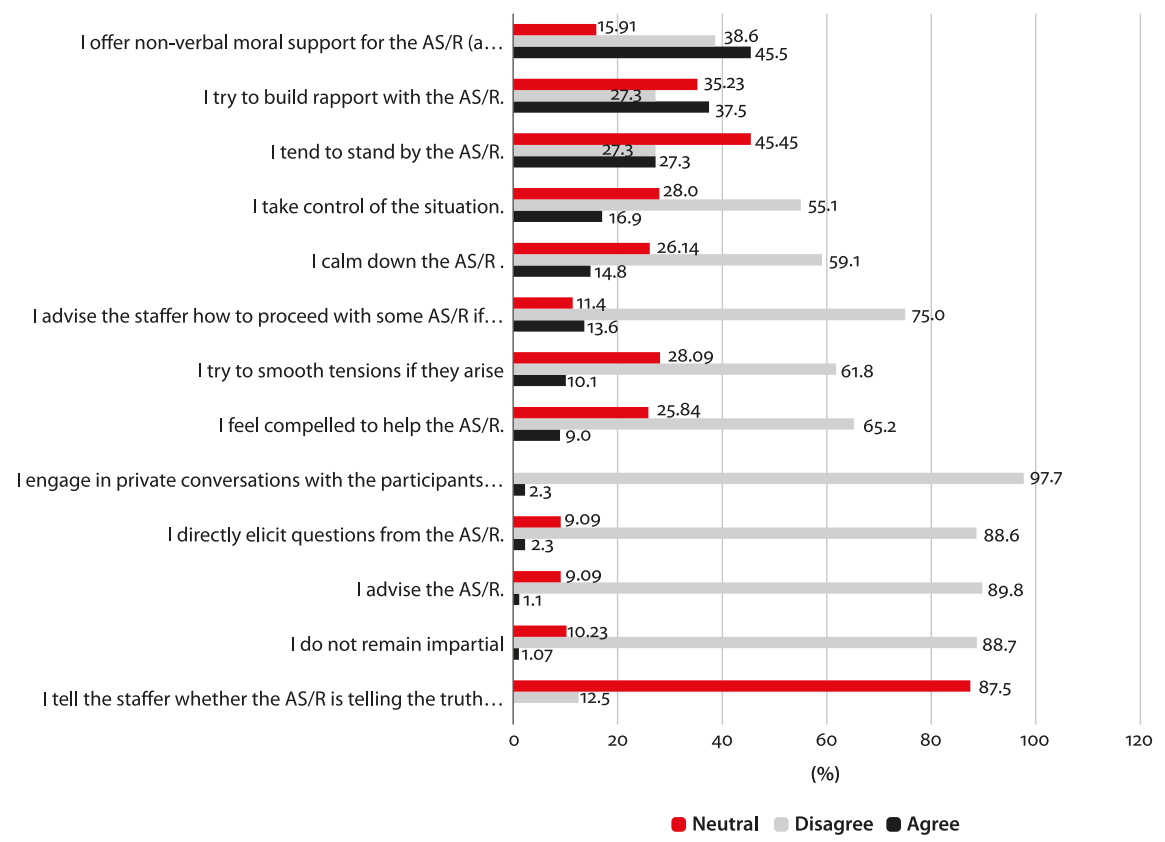

Graph 2. Observance of attitudes and actions related to impartiality

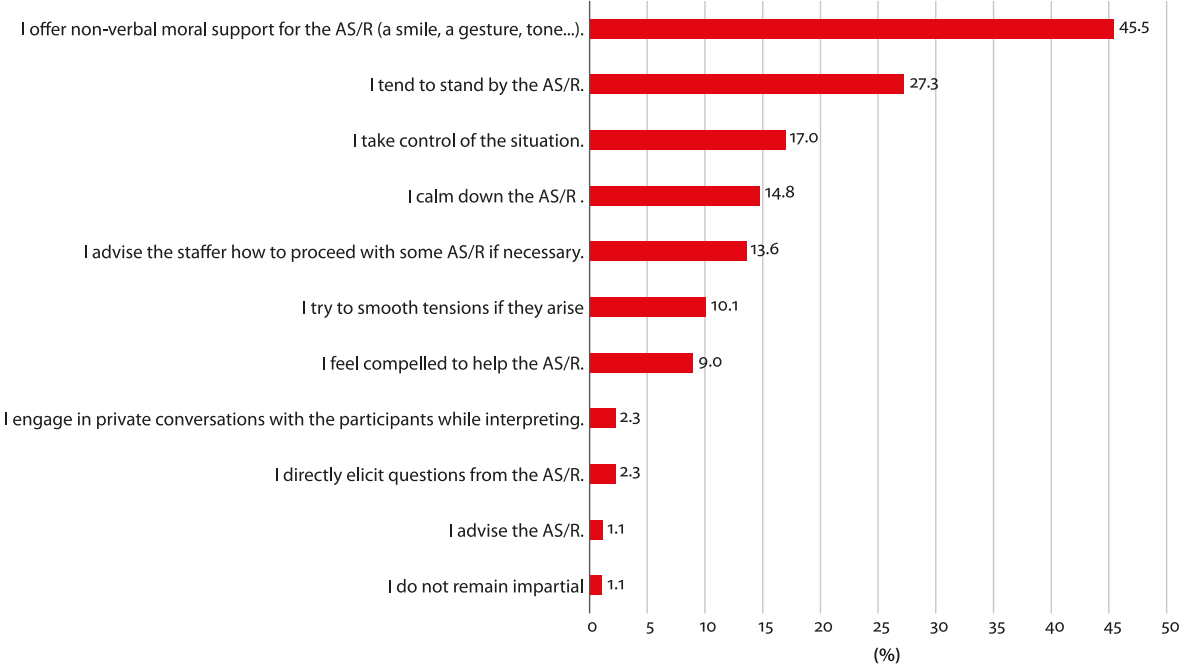

Graph 3. Explicit breach of impartial attitudes and actions 
It should be noted that an even higher percentage of respondents did not fully commit to strictly keeping to impartial conduct either, opting for the neutral position. The combined results of neutral stances and explicit breaches of the rule represent a deviation from impartiality (Graph 4 ). This deviation ranges from 2.3 percent for engaging in private conversations with the applicants to 72.7 percent for tending to stand by them.

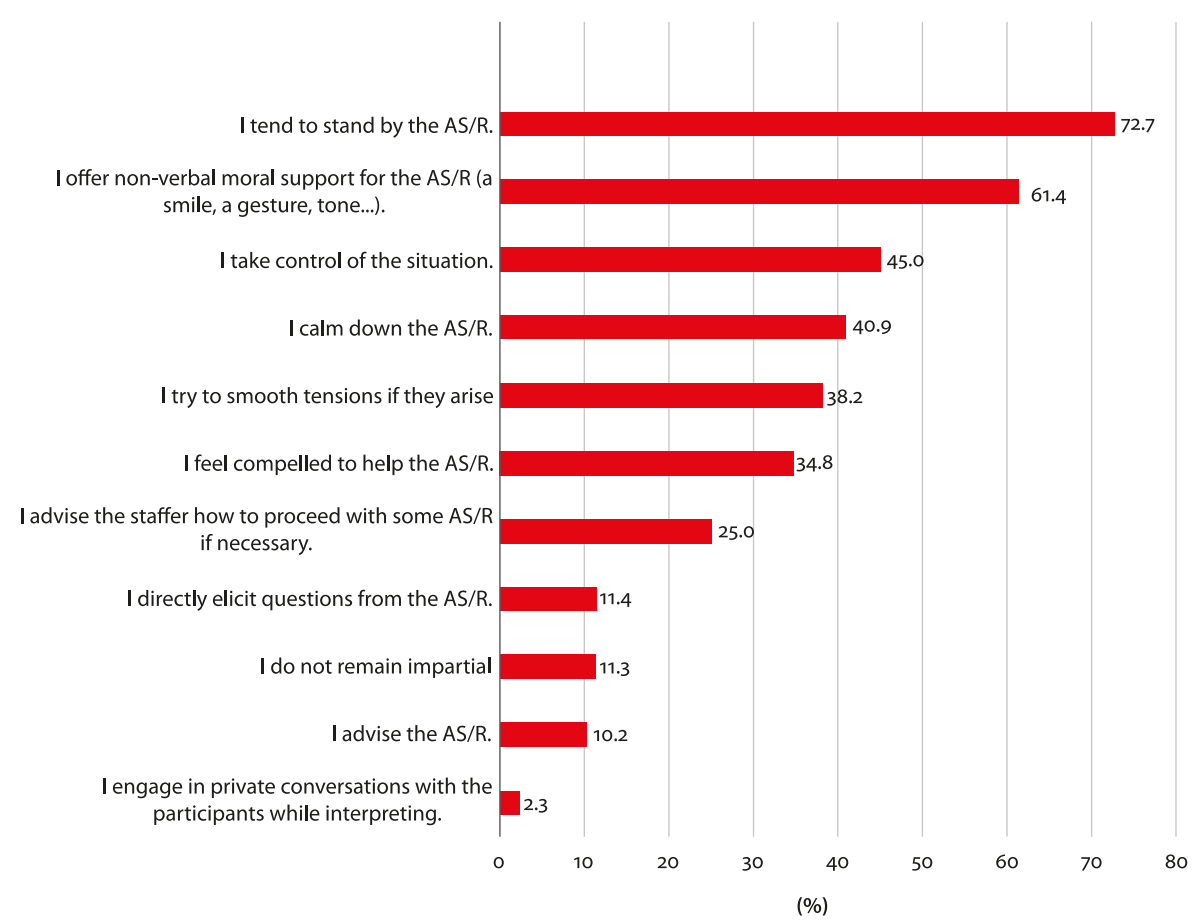

Graph 4. Deviations from impartiality. Combined results from explicit breach and neutral stand

Accuracy. Graph 5 shows results on actions related to accuracy and completeness.

Again, a number of actions related to this principle reveal some breaches of strict compliance with the rule.

The major explicit breach refers to summarizing; 25 percent admitted to complying with the request. The rest of actions range from 12.1 percent who said that they simplify language and concepts to 1.1 percent who directly skip culturally inappropriate questions.

As to deviations from accuracy-neutral stances plus explicit breaches(Graph 7), the highest score applies to summarizing when asked, reaching 48.9 


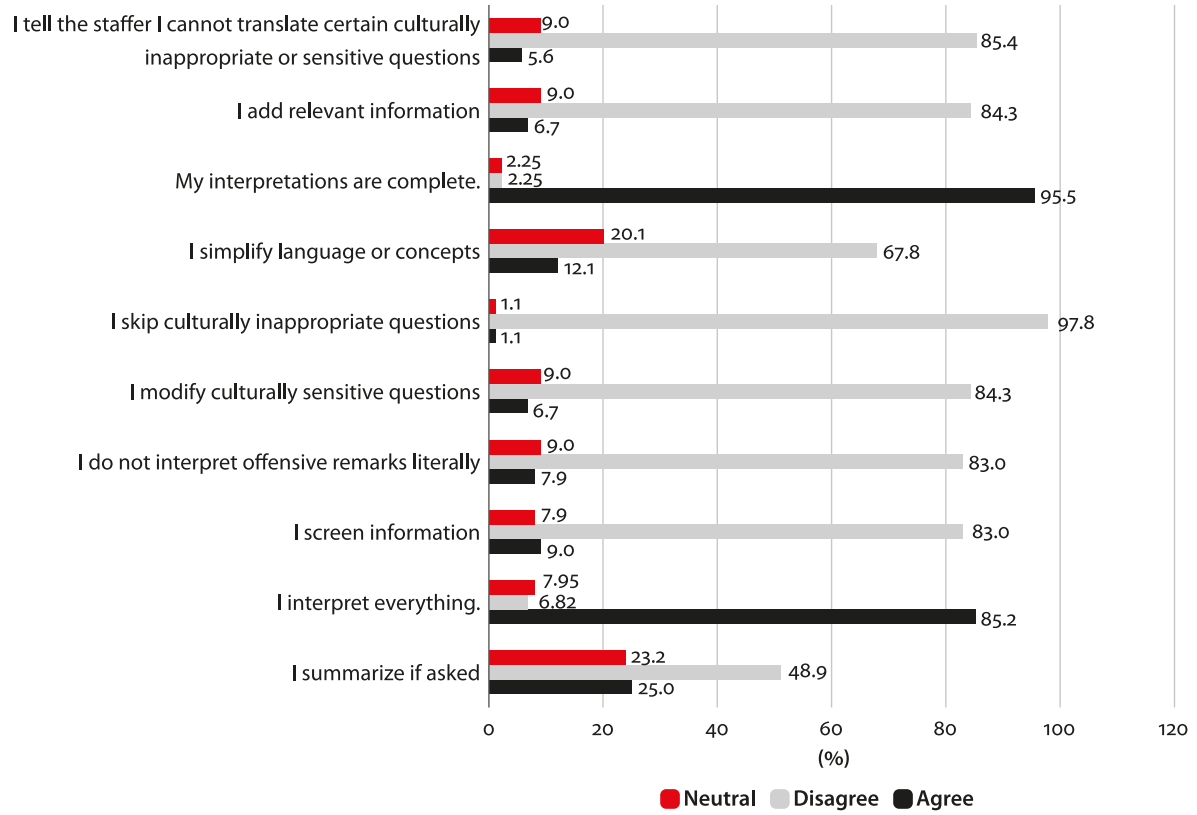

Graph 5. Observance of actions related to accuracy and completeness

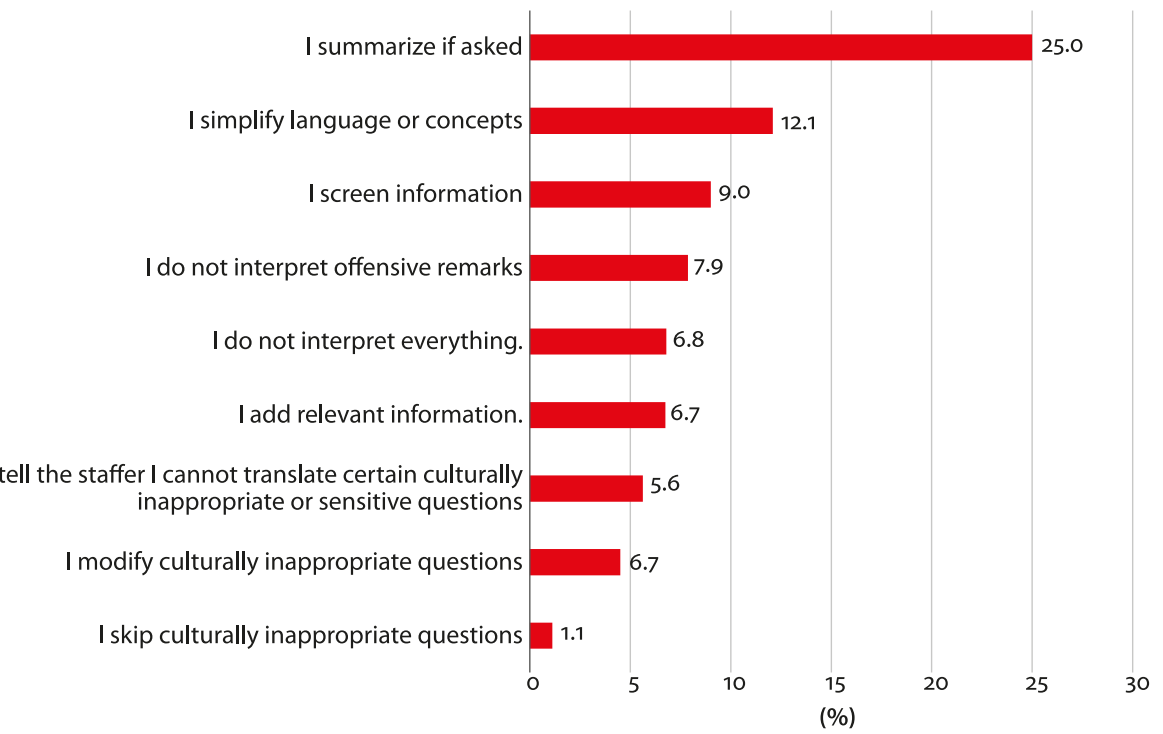

Graph 6. Explicit breaches of actions connected to accuracy and completeness ${ }^{3}$

3. The items "I interpret everything" and "I interpret offensive remarks" have been reversed in the graph for clarity purposes 
percent of the sample. The remaining deviations range from 32.20 percent for simplifying language or concepts to 2.2 percent for skipping culturally inappropriate or sensitive questions.

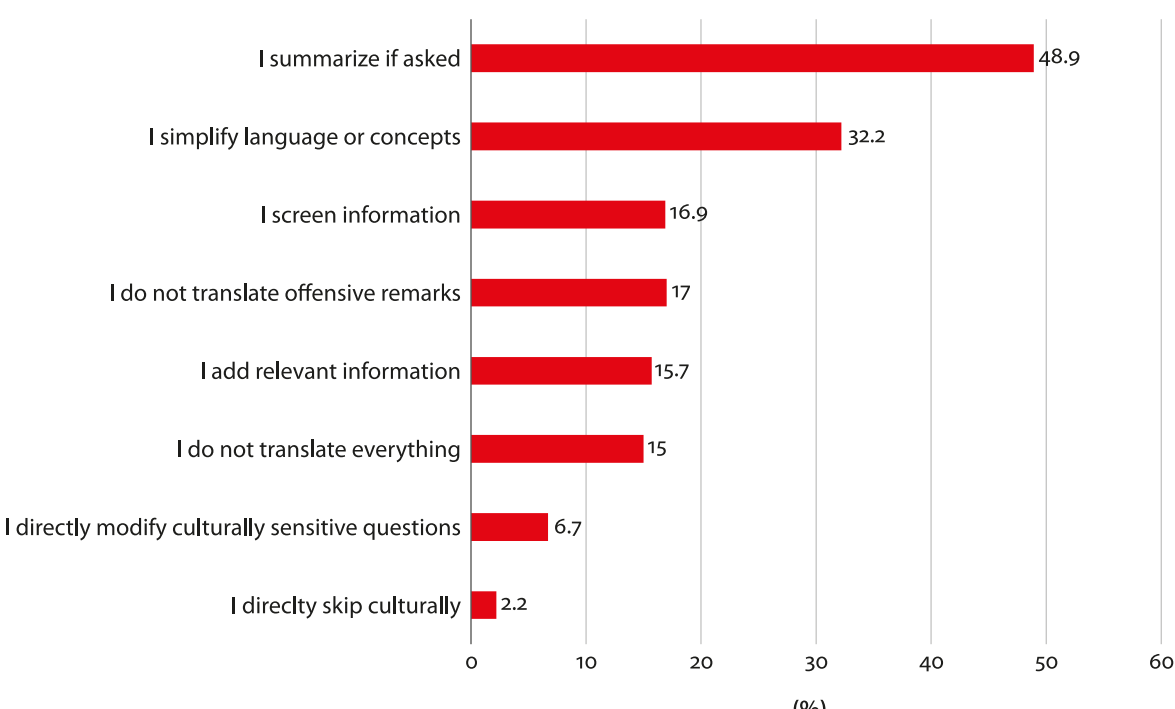

(\%)

Graph 7. Deviations from accuracy. Combined results from explicit breach and neutral stand

Finally, Graph 8 shows the mean percentage of attitudes and actions deviating from both principles. Findings show a 42.04 percent deviation from impartiality. In other words, impartial attitudes and actions represent 57.96 percent of the set of actions presented, that is, 30.74 percent lower than the self-perceived theoretical observance of the behaviour I remain impartial while interpreting. As for accuracy, deviation constitutes 15.9 percent from accuracy measured in the action; hence, compliance reaches 84.1 percent, i.e. 11.4 percent lower than the theoretical self-perception.

Additional data: some specific data from other areas of the project not directly addressed in this paper are included here since they might contribute to shed light on professionalism and familiarity with asylum contexts. First, confidentiality, as the third core principle of the code of ethics, was valued by 99 percent of respondents, one percent rated it as neutral and none declared it irrelevant. Responses mirrored initial appreciation when asked if they respected confidentiality. Secondly, speaking in the first person and taking notes constitute two professional standards of practice rarely practised by ad hoc or untrained practitioners: 87.5 percent and 85.4 percent employed them respectively. The remaining did not or 


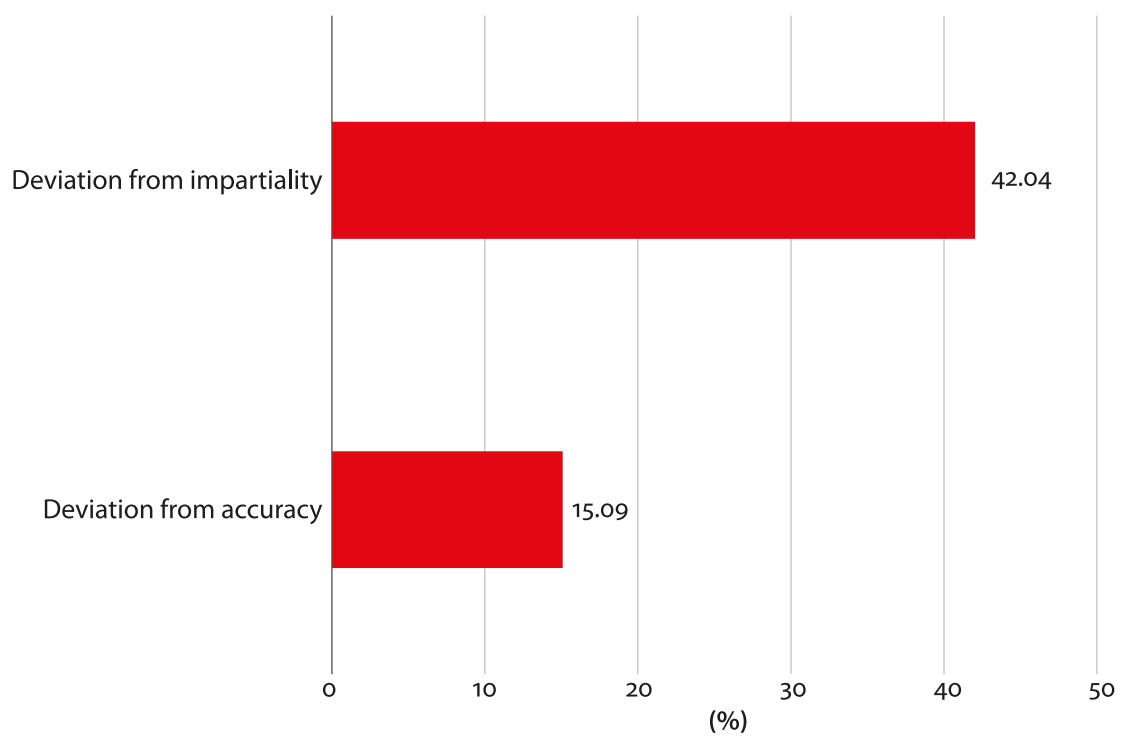

Graph 8. Mean of all actions deviating from impartiality and accuracy

were neutral. Finally, participants were asked if they had experienced unpleasant situations while interpreting in a refugee setting: 63.6 percent agreed, 23.9 disagreed and 12.5 were neutral.

\section{Discussion}

The goal of this study was to analyse the compliance with impartiality and accuracy by interpreters working in a refugee setting in the US through the analysis of their self-perceptions. The survey has shown discrepancies between the high appreciation and adherence to the principles and actual compliance. Findings show that most attitudes and practices related to professional ethics are generally observed but never unanimously reveal that participants' self-identification with the code's principles, though high, is actually lower than their endorsement of values. Moreover, this theoretical high self-identification or adherence is not subsequently reflected in actual attitudes and behaviours. Substantial deviations, measured through explicit breaches of norms or taking a neutral stand have been brought to light. Both active and passive positions reflect a lack of commitment to observe the principles unconditionally.

The highest diverging scores refer to attitudes affecting impartiality. Fishbein \& Ajzen, (1975) established that attitudes predispose individuals to behave in a particular manner. A favourable attitude towards the asylum-seeker -backed by 
almost three quarters of the sample- is likely to predict behaviour. Most prevalent diverted behaviours are directly connected to emotionally charged situations. It should be pointed out that a number of respondents had experienced unpleasant situations in this context. Non-impartial actions unrelated to emotional dynamics did not score as high. Advising officers and appellants as well as eliciting questions, although acknowledged by a minority, represent the most blatant breaches of the norm and reveal how interpreters hold an active role in the interaction. This stands in sharp contrast to the high levels of self-identification with the impartiality principle. These breaches could be explained by a great desire to help any party or by a need to place themselves in a stronger position of agency, exceeding the impartial role in both instances.

Regarding accuracy, the 10-point divergence found between self-identification with complete interpretation, on the one hand, and interpreting everything, on the other, suggests that for a number of participants, complete interpretation is not tantamount to interpreting everything. This is perfectly plausible when paralinguistic features, hesitations, repairs, repetitions or content considered irrelevant by interpreters are taken into account. These elements are expected to be rendered in certified court interpreting but not elsewhere. Summarizing, an action recognised by almost 50 percent of participants, constitutes the highest discrepancy with the preponderant self-perception of rendering complete interpretations. This behaviour can emerge as a response to an external demand, probably resulting from a lack of education on the part of the providers unaware of the role and function of interpreters (Tipton \& Furmarek, 2016) and unable, thereby, to manage their conduct properly. Time pressure can be an additional explanatory external demand on summarising and simplifying language and concepts, the second acknowledged deviation.

Both deviations from the accuracy principle could be accounted for by the interpreter's desire to facilitate the interaction dynamics inherent in difficult working conditions. A UNHCR (2010) report draws attention to the often-limited amount of time available to officers who usually have to prepare and conduct interviews. Simplifying could emerge out of empathy towards petitioners considered by the interpreter unable to understand alien or technical vocabulary and concepts. On the other hand, simplifying long convoluted recounts may reflect the interpreters' belief that they are better at telling their story (Fenton, 2004). It can also bring out a condescending attitude. Overall, commitment to accuracy presents a lower mean deviation from the norm compared to impartiality. This represents a further contradiction with the theoretical appreciation and adherence to the principle because it scored lower than impartiality. Nevertheless, this deviation again embodies a blatant contradiction with the solid endorsement of 
the principle. It may be worth highlighting that accuracy was not as appreciated as a principle as impartiality; however, actions did not deviate as much.

The rest of the actions related to both principles show fewer breaches. Since the sample consists of mostly certified and trained practitioners, the divergences cannot be attributed to a lack of knowledge of professional standards. Age and work experience could also be taken into account to explain this high degree of latitude. Practitioners with seniority tend to have strong personal autonomy (Goldstein, 1976; Ng \& Feldman, 2008). The combination of these factors could also contribute to explain findings.

\section{Conclusion}

This study reveals that despite majoritarian observance of most actions related to impartiality and accuracy by trained professionals working in American refugee settings, this observance is never complete. A large number of participants do not comply with a series of parameters and none complies with all of them all the time. Tipton \& Furnamek's (2016) claim about lack of empirical evidence for impartiality in interpreting in a refugee setting is confirmed in this study. Findings are in line with previous research conducted with much smaller samples on other continents. The above-mentioned UNHCR report (2010) observed the same gaps between guidelines and actual practice in a small number of interpreters working for member states of the European Union. Pöllabauer's (2004) and Fenton's (2004) conclusions about the situation in Austria and New Zealand yielded similar results.

Sympathy and caring for the disadvantaged surface as a priority suggesting that social solidarity is placed before professionalism, bringing into the open a clear dichotomy between professional beliefs and personal or even universal ethos. As Inguilleri (2010:153) pointed out: "Translators cannot escape the burden of their moral proximity disparate sets of rights and obligations and balance one ethical obligation against another". This internal force awakens interpreters' resistance in complying with the impartiality tenet. External forces in the form of difficult working conditions, in particular, time constrains and a lack of awareness of the role of the interpreter by providers, also contribute to hinder compliance with the accuracy principle. The observed deviations from these two core principles call into question the applicability of the code.

It might be high time for codes that still constrain the role of the interpreter to that of a mere conduit of messages to rethink their stance and perhaps openly establish minimal as opposed to maximal standards allowing for a specific degree 
of latitude that prioritizes universal ethics and takes contingencies into consideration. The findings presented here respond to self-perceptions, which may or may not coincide with actual practices. Other methodological approaches using more complex statistical analysis might have generated data that are more reliable. In addition, qualitative designs involving registration and analysis of interpreted events and/or registering practitioners' impressions could contribute to a better understanding of the dynamics behind explicit deviations from the code.

Disclosure statement: The author reported no potential conflict of interest.

\section{References}

AIIC 1999. Practical Guide for Conference Interpreters. Available at: http://aiic.net/p/628 Angelelli, Claudia. 2004a. Revisiting the interpreter's role: a study of conference, court, and medical interpreters in $\bar{\equiv} d a$, Mexico, and the United States. Amsterdam: John Benjamins Publishing Company. https://doi.org/10.1075/btl.55

Angelelli, Claudia. 2004b. Medical Interpreting and Cross-cultural Communication. Cambridge: Cambric $\equiv$ niversity Press. https://doi.org/10.1017/CBO9780511486616

Angermeyer, Philip Sebastian. 2015. Speak English or What? Code switching and Interpreter Use in New York City Courts. Oxford: Oxford University Press.

Bahadir, Sebnem. 2010. The task of the interpreter in the struggle of the other for empowerment: mythical utopia or sine qua non of professionalism? Translation and Interpreting Studies, 5(1), 124-139. https://doi.org/10.1075/tis.5.1.08bah

Baker, Mona. 2006. Translation and Conflict: A Narrative Account. London and New York: Routledge. https://doi.org/10.4324/9780203099919

Bancroft, Marjory, Lola Bendana, Jean Bruggeman \& Louis Feuerle. 2013. Interpreting in the gray zone: Where community and legal interpreting intersect. Transl 5(1), 94-113.

Bámbaren-Call, AnaMaria, Marjory Bancroft, Nora Goodfriend-Koven, Karen Hanscom, Nataly Kelly, Virginia Lewis, Cynthia Roat, Liliya Robinson \& Lourdes Rubio-Fitzpatrick. 2012. Interpreting Compassion A Needs Assessment Report on Interpreting for Survivors of Torture, Trauma and Sexual Violence. Available at http://voice-of-love.org/ Accessed 5/5/2019.

Barsky, Robert. 1996. The interpreter as intercultural agent in convention refugee hearings. The Translator, 2(1), 45-63. https://doi.org/10.1080/13556509.1996.10798963

Boéri, Julie \& Carol Maier (Eds.). 2010. Translation Interpreting and Social Activism. Granada: ECOS.

Boéri, Julie. 2015. Key internal players in the development of the interpreting profession. In Mikkelson, $\mathrm{H} \equiv \mathrm{\equiv}$ Renée Jourdenais (Eds), The Routledge handbook of interpreting (41-56). Oxon \& New York: Routledge.

Bossers, Ann, Jean Kernaghan, Lisa Hodgins, Lean Merla, Charlene O’Connor \& Monique Van Kessel. 1999. Defining and developing professionalism. Canadian Journal of Occupational Therapy, 66(3), 116-121. https://doi.org/10.1177/000841749906600303 
Davidson, Brad. 200o. The interpreter as institutional gatekeeper: The social-linguistic role of interpreters in Spanish-English medical discourse. Journal of Sociolinguistics (4)3, 379-405. https://doi.org/10.1111/1467-9481.00121

Dysart-Gale, Deborah. 2007. Clinicians and medical interpreters. Negotiating culturally appropriate care for patients with limited English ability. Family and Community Health 30, 237-246. https://doi.org/10.1097/01.FCH.0000277766.62408.96

Dragovic-Drouet, Mila. 2007. The Practice of Translation and Interpreting During the Conflicts in the Former Yugoslavia (1991-1999). In Salama-Carr, Myriam (Eds.), Translating and Interpreting Conflict. Amsterdam-New York: Rodopi BV, 29-40. https://doi.org/10.1163/9789401204385_004

EULITA European Association for Legal Interpreters and Translators. Code of Professional Ethics 2013. Available at https://eulita.eu/wp/wp-content/uploads/files/EULITA-codeLondon-e.pdf

Evetts, Julia. 2013. Professionalism: Value and ideology. Current sociology, 61(5-6), 778-796. https://doi.org/10.1177/0011392113479316

Fatahi, Nabi, Lena Nordholm, Beng Mattsson \& Michael Hellström. 2010. Experiences of Kurdish war-wounded refugees in communication with Swedish authorities through interpreter. Patient Education and Counselling, 78(2), 160-165. https://doi.org/10.1016/j.pec.2009.03.010

Fenton, Sabine. 2004. Expressing a well-founded fear: Interpreting in convention refugee hearings. Amsterdam: John Benjamins, 50, 263-270.

Fishbein, Martin, \& leek Ajzen. 1975. Belief, attitude, intention, and behaviour. Reading, MA: Addison-Wesley.

García-Beyaert, Sofia, Marjory Bancroft, Katherine Allen, Giovanna Carriero-Contreras \& Denis Socarrás-Estrada. 2015. Ethics and standards for the community interpreter. An international training tool. Th $\bar{\equiv}$ nunity Interpreter: An International Textbook. Culture \& Language Press 1-30. Available at https://static1.squarespace.com/static /5597f 49ce4bo7b7dda504921/t/55a6ad4be4bocc965b19ff73/143698669990o /Interior+Contents+TCII+Textbook+BW.pdf

Gentile, Paola. 2017. Political Ideology and de Deprofessionalisation of public service interpreting: The Netherlands and the United Kingdom as case studies. In Valero Garcés \& Rebecca Tipton (Eds.), 2017. Ideology, ethics and policy development in public service interpreting and translation. Bristol-Blue Ridge Summit PA, USA: Multilingual Matters. 63-83. https://doi.org/10.21832/9781783097531-008

Goldstein, J. 1976. Professional mobility in Israel's secondary schools: Results of a survey of attitudes. Educational Administration Quarterly, 12, 51-67. https://doi.org/10.1177/0013131X7601200205

Granger, Emily \& Martyn Baker. 2003. The role and experience of interpreters. Working with interpreters in mental health. Hove, UK: Brunner-Routledge.

Greenhalgh, Trisha, Nadia Robb. \& Graham Scambler. 2006. Communicative and strategic action in interpreted consultations in primary health care: a Habermasian perspective. Social Science \& Medicine, 63 (5), 1170-1187. https://doi.org/10.1016/j.socscimed.2006.03.033

Hatton, Diane \& Teresa Webb. 1993. Information transmission in bilingual, bicultural contexts: A field study of community health nurses and interpreters. Journal of Community Health Nursing, 10(3), 137-147. https://doi.org/10.1207/s15327655jchn1003_2 
Hebenstreit, Gernot, Alexandra Marics, and Jim Hlavac. 2017. Professional ethics and professional conduct. In UNHCR (Eds.), Handbook for Interpreters in Asylum Procedures, 70-84. Vienna: UNHCR. Available at http://www.unhcr.org/dach/at /trainingshandbuch

Hewit, William. 1995. Model code of professional responsibility for interpreters in the judiciary in court interpretation: Model guides for policy and practice in the State Courts. Available at shorturl.at/lFUVW

Hsieh, Elaine. 2008. "I am not a robot!" Interpreters' views of their roles in health care settings. Qualitative health research, 18(10), 1367-1383. https://doi.org/10.1177/1049732308323840

Hwa-Froelich, Deborah \& Carol Westby. 2003. Considerations when working with interpreters. Communication Disorders Quarterly, 24(2), 78-85. https://doi.org/10.1177/15257401030240020401

Inguilleri, Moira. 2010. Afterword by Moira Inguilleri. Exploring the task of the activist translator. In Boéri, Julie \& Carol Maier (Eds.), Translation Interpreting and Social Activism. Granada: ECOS. 152-155.

Kaczmarek, Lukasz. 2016. Towards a broader approach to the community interpreter's role: On correspondence between role perceptions and interactional goals. Interpreting, 18(1), 57-88. https://doi.org/10.1075/intp.18.1.03kac

Keselman, Olga, Ann Christin Cederborg, Michel Lamb \& Örjan Dahlström. 2010. Asylumseeking minors in interpreter-mediated interviews: what do they say and what happens to their responses? Child \& Family Social Work, 15(3), 325-334. https://doi.org/10.1111/j.1365-2206.2010.00681.x

Leanza, Yvan. 2005. Roles of community interpreters in pediatrics as seen by interpreters, physicians and researchers. Interpreting, 7(2), 167-192. https://doi.org/10.1075/intp.7.2.03lea

León Pinilla, Ruth. 2015. La interpretación en el contexto de refugiados. Camino hacia el bienestar. Ph. D. Dissertation. Universitat Jaume I of Castellón.

Metzger, Melanie. 1999. Sign language interpreting: Deconstructing the myth of neutrality. Washington DC: Gallaudet University Press.

Merlini, Raffaela. 2009. Seeking asylum and seeking identity in a mediated encounter: The projection of selves through discursive practices. Interpreting, 11(1), 57-92. https://doi.org/10.1075/intp.11.1.05mer

NAAJIT. National Association of Judiciary Interpreters and Translators. 2011. Available at https://ethics.iit.edu/ecodes/node/3570\#main-content

NCIHC. National Council on Interpreting in Healthcare. 2004. A National Code of Ethics for Interpreters in Health Care. NCIHC, Washington, DC Available at https://www.ncihc.org /assets/documents/publications/NCIHC\%20National\%20Code\%20of\%2oEthics.pdf

$\mathrm{Ng}$, Thomas W. \& Feldman, Daniel C. 2008. The relationship of age to ten dimensions of job performance. Journal of applied psychology, 93(2), 392. https://doi.org/10.1093/workar/wauoo3

NSGCIS. National Standard Guide for Community Interpreting Services. Available at https:// multi-languages.com/interpretations-shtml/interpreters_ethics-shtml/

Patel, Nimisha. 2003. Speaking with the silent: addressing issues of disempowerment when working with refugee people. Working with Interpreters in Mental health, 219-237. Available at http://www.refworld.org/docid/49b6314d2.html

Pennsylvania rules of professional conduct for interpreters. Act 172 of 2006 (42 Pa.C.S. $\$ \$ 4411(\mathrm{e})$. and 4431(e). Available at http://www.pacourts.us/judicial-administration /court-programs/interpreter-program/interpreter-rules-of-conduct 
Pöllabauer, Sonja. 2004. Interpreting in asylum hearings: Issues of role, responsibility and power. Interpreting, 6(2), 143-18o. https://doi.org/10.1075/intp.6.2.03pol

Roberts, Roda. 1997. Overview of community interpreting. In Silvana Carr, Roda Roberts, Aideen Dufour \& Dini Steyn (Eds.), The Critical Link: Interpreters in the Community. Amsterdam and Philadelphia: John Benjamins, 127-138. https://doi.org/10.1075/btl.19.03rob

Roy, Cynthia. 1999. Interpreting as a Discourse Process. New York: Oxford University Press, USA.

Rudvin, Mette. 2007. Professionalism and ethics in community interpreting: The impact of individualist versus collective group identity. Interpreting, 9 (1), 47-69. https://doi.org/10.1075/intp.9.1.04rud

UNHCR Self-Study Module 3: Interpreting in a Refugee Context. 2009. Available at https://www .unhcr.org/publications/manuals/4d944d229/3-refugee-annex-3-interpreting-refugeecontext.html

Splevins, Katie, Keren Cohen, Stephen Joseph, Craig Murray, \& Jake Bowley. 2010. Vicarious posttraumatic growth among interpreters. Qualitative Health Research, 20 (12), 1705-1716. https://doi.org/10.1177/1049732310377457

Tipton, Rebecca, \& Olgierda Furmanek. 2016. Dialogue interpreting: A guide to interpreting in public services and the community. Oxon \& New York: Routledge. https://doi.org/10.4324/9781315644578

Todorova, Marija. 2017. Interpreting at the border: 'Shuttle interpreting' for the UNHCR. CLINA: An Interdisciplinary Journal of Translation, Interpreting and Intercultural Communication, 3(2), 115-129. https://doi.org/10.14201/clina201732115129

Tribe, Rachel \& Jean Morrissey. 2003. The refugee context and the role of interpreters. Working with Interpreters in Mental Health, 198-218.

Tymoczko, Maria. 2003. Ideology and the position of the translator: in what sense is a translator "in between"? In Maria Calzada Perez (Ed.). Apropos of Ideology-Translation Studies on Ideology - Ideologies in Translation Studies, Manchester: St Jerome, 181-201.

UNHCR 2010. Improving Asylum Procedures: comparative analysis and recommendations for law and practice. Available at https://www.unhcr.org/4c7b71039.pdf

Valero-Garcés, Carmen. 2006. Formas de Mediación Intercultural, Traducción e Interpretación en los Servicios Públicos. Conceptos, datos, situaciones y práctica. Granada: Comares.

Wadensjö, Cecilia. 2001. Interpreting in crisis-The interpreter's position in therapeutic encounters. In Ian Mason (Ed.). Triadic Exchanges: Studies in Dialogue Interpreting. Manchester: St. Jerome, 71-85.

Wadensjö, Cecilia. 1992. Interpreting as interaction: On dialogue-interpreting in immigration hearings and medical encounters. Ph. D. Dissertation, Linköpings universitet. Published by Routledge in 2014 Interpreting as interaction.

\section{Appendix 1. Partial questionnaire for interpreters working for refugees in the US. Parts 1, 3, 4}

Adapted format for word processor

Q1. This survey is part of a research project seeking to examine language access and language mediation for asylum seekers and refugees in the US, particularly in the Southern 
border but not restricted to it. The principal investigator is a professor from the Universitat Jaume I, Castellón, Spain, who is visiting the University of Texas at San Antonio. You are invited to participate in this research project because you are an interpreter who works or has worked with people seeking asylum in the US* in any context (not only during the asylum process) either onsite or offsite. Your participation in this research study is voluntary and anonymous. The procedure involves completing a survey consisting of 43 questions. It will take you approximately 16 minutes. Some questions require a response before you can continue. The survey does not contain information that will personally identify you or the agency you work for if any. The results of this study will be used for scholarly purposes only and may be shared with the universities involved. Your input and contribution is highly valuable as it will contribute to identify strengths and weaknesses in interpreting in this area. Thank you for your participation.

*If you have never interpreted for asylum seekers/ refugees / immigration in the US, this survey is not meant for you.

Q2. Do you consent to participate in this research project? Skip to end of the survey if you do not consent to participate in this research project $=$ No

Q3. Age range

Q4. Gender

Q5. Mother tongue

Q6. If other, enter your mother tongue.

Q7. Working language (1) besides English.

Q8. Working language (2) besides English if applicable. Do not answer this question if you only work with a pair of languages.

Q9. Working language (3) besides English if applicable.

Q10. If other or if you have a fourth language, enter your working language(s).11 Level of education

Q11. Level of education

If college, master's or doctoral degree please specify

Q12. Did you have any specific training as an interpreter?

Yes, one workshop or seminar lasting less than 10 hours

Yes, a few workshops and seminars lasting less than 10 hours each

Yes, a short course of 40 hours or more

Yes, I have a bachelor's degree in Interpreting or in Translation and Interpreting

Yes, I have a master's degree in Interpreting

Yes, I have a master's degree in Translation and Interpreting

Yes, I have an official certification in interpreting

Q13. Please, specify your certification

State Certified Court Interpreter.

Federally Certified Court Interpreter (FCCI).

Professionally Qualified Interpreter (PQ except for Spanish, Navajo and Haitian Creole).

Certified Medical Interpreter (CMI). NAJIT

RID certification

Other 
Q14. Which best describes your current status as an interpreter when working in asylum seekers/refugee/immigration contexts

Q15. Which of the following best describes the way you self-identify as an interpreter if so? You can select more than one option.

Conference interpreter

Court interpreter

Health interpreter

Community interpreter

Other

Q16. How long have you worked as an interpreter or interpreter/translator?

Q17. Did you have any specific training that has helped you to work in AS/R/I contexts? From now on AS/R/I will stand for asylum seeker/refugees/immigration. Contexts or in these contexts or settings may also be used.

Q18. If so, what sort of specific training have you had that has helped prepare you to work in these contexts?

Q19. Please, specify what kind of training you had.

Q20. Who hires you usually to work in these contexts?

Q21. In what kind of settings do you interpret for AS/R/I contexts? You can click on more than one option.

Legal counselling, Detention centers, Credible fear interview, Asylum hearings, Medical care, Mental health care, Other

Q22. Rate the relevance of the following features for effective interpreting in these contexts Say whether you find it relevant, irrelevant or neutral. Impartiality, Completeness of delivery, Accuracy, Confidentiality

[Abridged question. 4 of 25 items]

Q23. According to your interpreting experience rate the following statements as agree, disagree or neutral. AS/R is used for asylum seeker or refugee. The term staffer refers to the service provider: police or immigration officer, judge, attorney, social worker, medical staff, volunteer, etc. you interpret for. [Multiple choice: agree, disagree or neutral. Questions were randomized]

The participants ask me for advice or my opinion while or after interpreting.

The participants ask me to carry out tasks other than interpreting.

The staffer asks me whether the AS/R seeker is telling the truth.

I am asked to clarify information for the AS/R after the meeting is over or during a break.

The staffer asks me to calm down the AS/R.

The staffer asks me to summarize.

Other staffers in the facilities view you with scepticism, discomfort or mistrust.

I translate everything.

I tend to stand by the AS/R.

I speak in the first person.

I am allowed to use a dictionary or other material while interpreting.

The participants speak directly to me.

I monitor conversational turns. 
I make direct eye contact with the participants.

I try to build rapport with the AS/R.

I advise the AS/R.

I tell the staffer whether the AS/ $\mathrm{R}$ is telling the truth if asked.

I carry out tasks other than interpreting if I am asked to.

I offer non-verbal moral support for the AS/R a smile, a gesture, tone.

I have experienced fear in certain interpreting assignments.

I receive information before interpreting.

I remain neutral no matter what.

I calm down the AS/R

I have experienced unpleasant situations.

I clarify information for the AS/R after the meeting is over or during a break.

I engage in private conversations with the participants while interpreting.

I directly elicit questions from the AS/R.

I advise the staffer how to proceed with some AS/R if necessary.

I speak in the third person.

I abide by confidentiality.

I summarize if I am asked to. [Abridged. 31 items related to the three principles of 40]

\section{Appendix 2. Full results of demographics and professional profile}

1. Age range

32.6 percent were over 60. 22.5 percent over 50. 24.7 percent over 40. 16.9 percent over 30

and 3.4 percent less than 30 .

2. Gender

76.4 percent female and 23.6 percent male.

3. Mother tongue

Other than Spanish and English, the highest proportion was represented by Russian native speakers, 6.7 percent of the sample. The rest of languages were minoritarian in this field, ranging from 4 native speakers of Arabic, 4 of Italian and 4 of Romanian accounting for 4.5 percent of the sample each, French and Portuguese with 3 native speakers each and 1.1 percent or 1 speaker of Mandarin, Punjabi, Turkish and Polish.

4. Working languages

The percentage of working languages pairs reflected the interpreters' mother tongues only to a certain extent with English-Spanish on top with 64 per cent, English-French accounting for 12.4 percent, English-Russian 6.7, English-Arabic for 5.6, Portuguese 4.5 percent and the rest of the working language combinations representing 1.1 percent, English combined with Mandarin, Turkish, Lingala, Punjabi, Turkish, Ukrainian, Urdu and Vietnamese.

5. Education level

1 respondent had a postdoctoral degree, 6.7 percent had a doctoral degree, 31.5 percent of the sample had a graduate degree 10.1 percent had an associate degree or some unfinished college education. 2 had a high school diploma and only one declared less than high school. 


\subsection{Specific degree}

7 respondents did not offer a clear answer stating just $\mathrm{MA}, \mathrm{BA}, \mathrm{PhD}$ or the name of the university. However, 9 of them acknowledged an MA or BA in Translation and Interpreting, 8 in Spanish, 4 in Business, 4 in Law, 4 International Relations, 4 Education, 2 in Applied Linguistics, 2 in Communication and a number of unique different degrees within the humanity field like Education, History, Humanities, Music and Computing.

6. Specific training in interpreting

10 people admitted not having any training at all in interpreting, which amounts to 9.6 percent of the sample. 4 people had a master's degree in interpreting and 7 people had a BA. It could be that 4 of the ones with a master's also had the BA since the survey did not force them to choose just one option. The rest of the sample had participated in seminars, workshops and courses ranging from less than 10 hours to more than 40 hours. Per language combinations, the mother tongue with the highest level of training was Spanish with 9 of them in possession of a MA. Non-European mother tongues had mostly taken short courses.

\subsection{Official accreditation}

59 percent of the sample held an official certificate for interpreting. 71.7 percent were state certified court interpreters, 24.5 percent were certified medical interpreters. The rest of them were federally-certified, professionally qualified or had a NAJIT or RID diploma.

6.2 Specific training to work with asylum seekers

50.6 percent of them had no specific training to work with asylum seekers. Among the almost other 50 percent who did receive training, 21 referred to court and/or legal settings, 13 to asylum and/or immigration settings and 2 to psychology. There were also the following single responses: social work or administrative settings, survivors of trauma, health issues among at risk populations and two participants acknowledged work experience in law firms, a chair for an immigrant rights committee and a Department of Justice accredited representative.

7. Job status

78.7 percent worked as contractor freelancers, $9.0 \%$ were volunteers within non-profit organizations. 6.7 percent were agency employees, 3.4 percent, non-profit organization employees and 2.2 percent were government employees.

8. Job self-perception

The vast majority of them, 66.3 percent, described themselves as court interpreters. 49.4 percent also described themselves as conference interpreters since they were allowed to choose more than one option. The rest opted for health interpreters, community interpreters and others (18 percent) identified themselves as immigration, legal, criminal justice, business and oil and gas interpreters. Some others chose descriptions related to modes of interpreting like simultaneous, consecutive, telephone or even to the number of languages as with multilingual interpreters.

9. Work settings with asylum seekers

In this order they work in asylum hearings, legal counselling, credible fear interview, detention centres and medical care. 


\section{Experience}

The sample has a long experience, more than 30 percent of them have worked in this setting for over 10 years, 36 percent for over 20 years. 16.9 percent have less than 5 years' experience.

\subsection{Remote interpreting experience}

Just over 53 percent of them had conducted interpreting remotely and about half of them had only done less than 10 over-the-phone interpreting assignments for asylum seekers. 10 percent had interpreted more than 100 times over the phone. On the contrary, only one respondent did not have any onsite experience, only remote.

10.2 In person interpreting experience

The remaining 28.4 percent had conducted more than 100 interpreting assignments onsite, 17 percent between 50 and 10o. 11.4 up to 50 and 42 percent less than 20.

\section{Geographical area}

While working onsite, the majority of respondents mentioned Texas (26) followed by California (18), followed by New York and the East Coast. The rest mentioned a wide variety of states and regions across the continental US.

\section{Résumé}

Cet article examine les principes fondamentaux du professionnalisme en se concentrant sur le code de l'éthique en tant qu'axe central. Une attention particulière est portée sur les difficultés d'appliquer deux des principes fondamentaux des codes éthiques pour l'interprétation avec des réfugiés : l'impartialité et la précision. Le but de cet article est d'analyser comment les interprètes se soumettent à ces principes et comment ils s'y identifient lorsqu'ils travaillent avec des réfugiés. 96 Interprètes travaillant aux États-Unis ont répondu à une enquête sur leur propre perception au sujet du respect des principes et de la réalité des actions entreprises. Les résultats montrent qu'un grand nombre d'interprètes ne respectent pas ces principes bien qu'ils aient auparavant déclaré les soutenir et s'y identifier. L'impartialité présentait plus d'écart que de la précision. Les exigences internes et externes se sont avérées plus fortes que l'adhésion au code. C'est pourquoi, il apparaît nécessaire de repenser et d'améliorer les codes éthiques pour l'interprétation dans un contexte de travail avec des réfugiés.

Mots-cles: interprétation, réfugiés, codes d'éthique, impartialité, précision 


\title{
Address for correspondence
}

\author{
Amparo Jiménez Ivars \\ Universitat Jaume I \\ Departament de Traducció i Comunicació \\ Avda. Sos Baynat s/n \\ 12071 Castelló \\ Spain \\ jimenez@uji.es
}

\section{Author Queries}

- Please provide a complete reference for the citation '(Baixauli 2017), (Angelelli, 2004), (Bancrof (2017)), (Dysart-Gale, 2005), (Boeri \& Maier, 2015), (Granger \& Baker, 2002), (Inghilleri, 2012), (García-Beyaert, Bancroft, Allen, Carriero-Contreras, \& Socarrás-Estrada, 2009)' in this article.

- Please provide a citation for the reference id "CITo002 (Angelelli, Claudia. (2004a)), CITo003 (Angelelli, Claudia. (2004b)), CIToo10 (Boéri, Julie \& Carol Maier (Eds.). (2010)), CIToo14 (Dysart-Gale, Deborah. (2007)), CIToo21 (García-Beyaert, Sofia, Marjory Bancroft, Katherine Allen, Giovanna Carriero-Contreras \& Denis Socarrás-Estrada. (2015)), CIToo24 (Granger, Emily \& Martyn Baker. (2003))" since citation is missing in the article. 